\title{
Six New Species of Sawflies from Gansu and Qinghai Provinces of China (Hymenoptera: Tenthredinidae)
}

\author{
Attila Haris \\ (Hungarian Natural History Museum, H-8142 Urhida, Petöfi u. 103, Hungary)
}

\begin{abstract}
Three new Tenthredinidae species are reported from Gansu and three from Qinghai Provinces of China. Tenthredo (Tenthredo) sinotemula sp. nov., Tenthredo (Tenthredella) labrangensis sp. nov. and Tenthredo (Tenthredella) sinosimplex sp. nov. are described from Gansu, Tenthredo (Tenthredella) rolleri sp. nov., Tenthredo (Tenthredella) qinghaiensis sp. nov. and Tenthredo (Tenthredella) yunningsiensis sp. nov. from Qinghai Province.
\end{abstract}

Key words: Hymenoptera; Symphyta; Tenthredinidae; New species; Gansu; Qinghai; China

\author{
中国甘肃和青海省叶蜂类六新种记述 \\ （膜翅目：叶蜂科） \\ Attila Haris \\ (Hungarian Natural History Museum, H-8142 Urhida, Petöfi u. 103, Hungary)
}

摘要: 记述了叶蜂科采自甘肃的 3 个新种: Tenthredo (Tenthredo) sinotemula sp. nov., Tenthredo (Tenthredella) labrangensis sp. nov.和 Tenthredo (Tenthredella) sinosimplex sp. nov.; 采自青海的 3 个新种: Tenthredo (Tenthredella) rolleri sp. nov., Tenthredo (Tenthredella) qinghaiensis sp. nov.和 Tenthredo (Tenthredella) yunningsiensis sp. nov.

关键词: 膜翅目; 广腰亚目; 叶蜂科; 新种; 甘肃; 青海; 中国

中图分类号：Q969.54+2.6 文献标识码：A 文章编号：0254-5853-(2009)03-0319-08

This is the fifth part of our series study of the Chinese sawfly material of Slovak expeditions (Haris \& Roller, 1998, 1999a, b, 2007). In the previous parts, materials from Yunnan (Haris \& Roller, 1998, 1999a, b) and Gansu Provinces (Haris \& Roller, 2007) were studied. The sawfly fauna of Qinghai Province is entirely unknown. On the sawflies of Gansu, one species is reported, namely Taxoblenus rufipes Wei and Nie, 1999 ( Wei \& Nie, 1999) and also other five species were reported by Haris \& Roller (2007), namely Tenthredo maculiger ssp. rupico (Konow, 1908), Taxoblenus longispinosus Haris and Roller, 2007, Tenthredo hajeki Haris and Roller, 2007, T. sinokrali Haris and Roller, 2007 and T. ruzickai Haris and Roller, 2007.

\section{Materials and Methods}

This small collection contains 37 specimens of 16 species (data of 14 species are published here, 11 specimens of 2 Pachyprotasis spp. remained unidentified). The studied material was collected by Dr. Jan Růžička, Dr. Jan Hájek and Dr. David Král Czech entomologists during their collecting trip to the Provinces in 2005. The material was sent to the author for identification by Dr. Ladislav Roller, a Slovak insect physiologist and sawfly researcher. Subgeneric classification of each species is given between their generic and specific name in bracket where available. Holotypes are deposited in the Hymenoptera Collection of Kunming Institute of Zoology, Yunnan, China, paratypes are in the Slovak National Museum, Bratislava and the Hungarian Natural History Museum, Budapest.

Abbreviations: KIZ - Kunming Institute of Zoology; SNM - Slovak National Museum, Bratislava-PozsonyPressburg; HNHM - Hungarian Natural History Museum, Budapest. 


\section{Descriptions}

2.1 Tenthredo (Tenthredo) sinotemula sp. nov. (Fig. 2, 11,17)

Material.-Holotype, female (KIZ): “ China, Gansu Province, Xiahe (=Labrang) env., $35^{\circ} 11.3^{\prime} \mathrm{N}, 102^{\circ} 30.6^{\prime} \mathrm{E}$, 3043 m (GPS), 19-22. vi. 2005, J. Hájek, D. Král and J. Rúzitschka leg. ".

Female (Fig. 17). Head black, whitish yellow: gena, lower inner orbit (below antenna), narrow, lower outer orbit (up to half of eyes), clypeus, labrum, mandibles (except brown apices), palpi, small, triangular supraclypeal area and small spot at inner-upper corner of eye. Lower outer orbit pale yellowish brown (behind narrow whitish yellow strip) up to half of eye. Antenna black. Pronotum whitish yellow with narrow anterior black margin. Tegula, anterior $2 / 3$ of mesoscutellum, postscutellum, metascutellum and metanotum behind metascutellum whitish yellow. Mesonotum and metanotum balck both with narrow posterior whitish yellow margin. Mesopleuron whitish yellow with longitudinal median black strip. Mesosternum black. Metepimeron, metasternum, mesepisternum and katepimeron whitish yellow with narrow black margins. Legs whitish yellow. Front and middle tibiae and femora
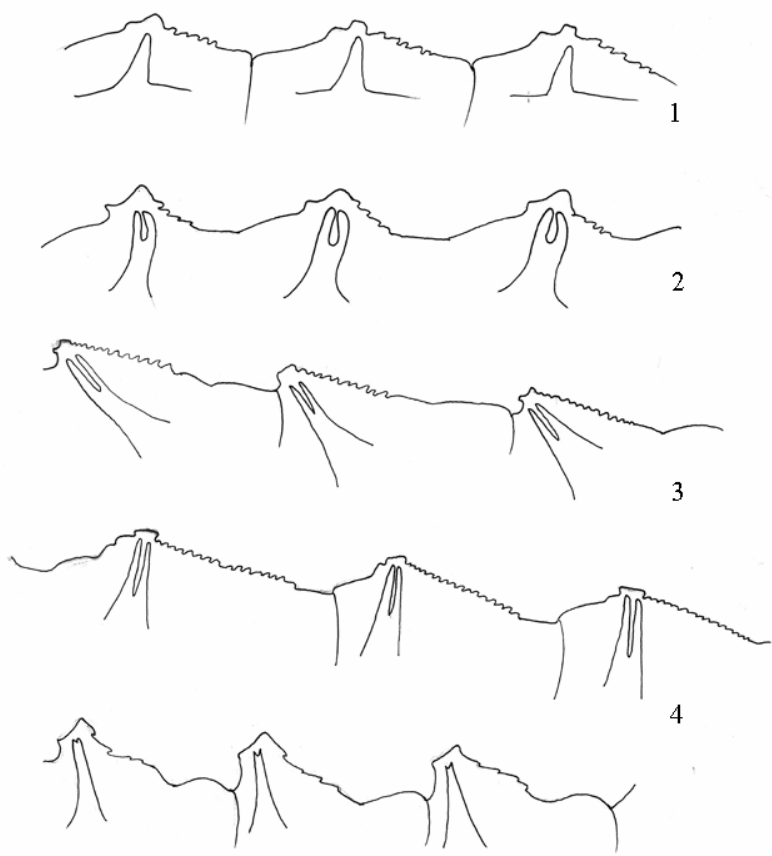

Figs. 1-5 5th-7th serrulae of five new species of Tenthredo genus

1: T. labrangensis sp. nov.; 2: T. sinotemula sp. nov.; 3: T. qinghaiensis sp. nov.; 4: T. sinosimplex sp. nov.;5: T. rolleri sp. nov. with longitudinal black strip. Hind femora and all tarsi black. Coxae pale whitish yellow, hind coxa with narrow longitudinal black strip. Wings hyaline, venation including stigma, costa, and subcosta blackish brown. Anal cell of hind wing with petiolate. Abdominal tergites black. Posterior third of propodeum, lateral triangular flecks on 2nd tergite, small, rounded lateral flecks on tergite 4 finally 3rd and 9th tergites entirely whitish yellow. Lateral and ventral side of abdomen whitish yellow. Ovipositor whitish yellow with narrow black apical margin. Head above (including vertex, temples and frontal area) very densely, moderately roughly and deeply punctured, moderately shiny. Mesonotum very densely, finely and uniformly punctured with small punctures, hardly shiny. Mesoscutellum moderately densely, shallowly and uniformly punctured shiny. Mesoscutellar appendage moderately shiny with few deep and moderately large, sporadic punctures. Metascutellum smooth, slightly shiny. Mesopleuron with minute, shallow and dense punctures, moderately shiny. Mesopleuron and mesoscutellum bluntly and subpiramidally elevated. Mesosternum without thorn. Abdominal tergites with fine and shallow surface microstriation, moderately shiny. Microstriation on propodeum very fine and shallow, shiny. Ratio of
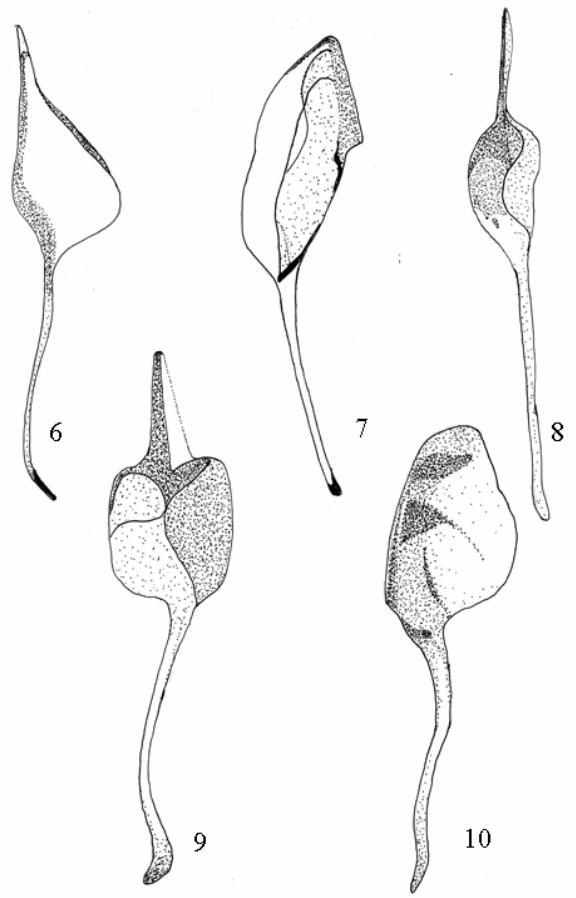

Figs. 6-10 Penis valve of five species of Tenthredo genus 6: T. rolleri sp. nov.; 7: T. yunningsiensis sp. nov.; 8: T. pseudograhami Wei, 2002 (after Wei); 9: T. flatopectalina Wei, 2002 (after Wei); 10: T. reversimaculeta Wei, 2002 (after Wei). 
antennal segments: $11: 7: 26: 18: 18: 14: 13: 10: 10$. Antenna short, about as long as head and thorax (excluding propodeum) combined. OOL : POL : OCL: $19: 7: 10$. Head with complete occipital carina starting from gena up to middle of vertex. Postoccellar furrows straight, parallel and deep reaching hind margin of head. Supraantennal tubercles not visible. Clypeal emargination rounded about $1 / 3 \mathrm{x}$ as deep as clypeal median length. Gena about as long as diameter of front ocellus. Frontal area slightly but clearly indicated by ridges, elongated and opened below. Head and thorax with whitish and moderately long pubescence, about $0.8 \mathrm{x}$ as long as diameter of front ocellus. Mesoscutellum with moderately long whitish pubescence about as long as diameter of front ocellus. Length of hind basitarsus : length of inner hind tibial spur: $5: 3$. Subapical tooth of claw shorter than apical tooth (Fig. 11). Length of hind tibia: length of ovipositor: $90: 55$. Serrulae $5-7$ with 4 larger teeth (Fig. 2). Length of body: $10.0 \mathrm{~mm}$, length of fore wing: $11.5 \mathrm{~mm}$.

The new species is somehow similar to Tenthredo brevivertexila Wei, 2002 (Nie \& Wei, 2002) although lancet and serrulae are completely different (compare with Fig. 5 a, b in Nie \& Wei, 2002). Furthermore, $T$. brevivertexila has hind femur with black strip and the black parts of body with distinct purplish luster, dorsal part of tergites 1-2 and 4-7 entirely black, tergite 3 entirely pale. The new species is also similar to the Palaearctic Tenthredo (Temuledo) temula Scopoli, 1763. Head of Tenthredo temula only sporadically and shallowly punctured, shiny. Propodeum without yellow hind margin and 2nd abdominal tergite without lateral triangular spot. Thorax and abdominal sternites entirely black (except narrow margin of tegula). Clypeus slightly and widely emarginated, clypeal emargination about $0.2 \mathrm{x}$ as deep as clypeal median length. Femora black, tibiae without longitudinal black strip. In opposite, the new species has head above very densely, moderately roughly and deeply punctured. Posterior third of propodeum, lateral triangular flecks on 2nd tergite, small, rounded lateral flecks on tergite 4, 3rd and 9th tergites are entirely whitish yellow in the new species. Front and middle tibiae and femora of the new species with longitudinal black strip. Furthermore clypeal emargination is rounded and about $1 / 3 \mathrm{x}$ as deep as clypeal median length. Tenthredo temula has head and mesonotum glabrous and lustrous. This is the reason why the new species does not run to subgenus Temuledo Zhelochovtsev, 1988 in Zhelochovtsev's key (Zhelochovtsev, 1988). The specific name refers to the distribution: sino means Chinese and also to its similarity to Tenthredo temula.
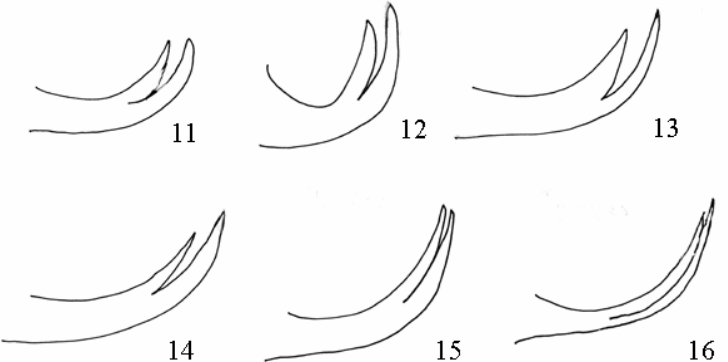

Figs. 11-16 Claw of six new species of Tenthredo genus 11: T.sinotemula sp. nov.;12: T. labrangensis sp. nov.; 13: T. sinosimplex sp. nov.; 14: T. qinghaiensis sp. nov.;15: T. rolleri sp. nov.;16: T.yunningsiensis sp. nov.

\subsection{Tenthredo (Tenthredella) labrangensis sp. nov.}

(Fig. 1,12,18)

Material.-Holotype, female (KIZ): "China, Gansu Province, Xiahe (=Labrang) env., $35^{\circ} 11.3^{\prime} \mathrm{N}, 102^{\circ} 30.6^{\prime} \mathrm{E}$, 3043 m (GPS), 19-22. vi. 2005, J. Hájek, D. Král and J. Rúzitschka leg. ”.

Female (Fig. 18). Head and antennae entirely black. Clypeus, labrum, mandible (except brown apex) and palp white. Thorax black, hind pronotal corner, apex of supraantennal tubercle, basal spot on tegula and cenchri white. Coxae and trochanters black. Femora red below, black above. Tibiae and tarsi red. Wings hyaline, costa and stigma reddish brown, subcosta and other veins black. Tergites 3-4 and basal, anterior strip on both sides of tergite 5 red, other tergites black. Sternites and ovipositor white but ovipositor with brown apex. Head densely, roughly, moderately deeply punctured, slightly shiny but vertex matt. Mesonotum with moderately dense, moderately deep small punctures. Sculpture between mesonotal punctures densely granulated and matt. Mesoscutellum with moderately deep, moderately large sporadic punctures, shiny. Mesoscutellar appendage laterally roughly wrinkled but smooth and slightly shiny in middle. Metascutellum finely wrinkled transversally with moderately deep punctures between wrinkles, moderately shiny. Mesopleuron very densely and uniformly punctured, hardly shiny. Punctures on upper mesopleural corner rough. Abdominal tergites with fine, superficial microstriation, moderately shiny. Propodeum with very fine superficial granulation, shiny. Ratio of antennal segments: $11: 9: 32: 22: 15: 15: 14$ : 11. Antenna short, about as long as head and mesonotum combined. OOL : POL : OCL: $26: 7: 28$. Head smooth, with only suture-like trace of occipital carina, dilated 
behind eyes. Postocellar furrows divergent, straight, moderately deep and reaching hind margin of head. Clypeus short. Clypeal emargination wide and about $1 / 3 \mathrm{x}$ as deep as clypeal median length. Supraantennal tubercles well separated from scape. Frontal field rectangular, separated by furrows. Mesopleuron flat, mesosternum without thorn. Mesoscutellum slightly bulging. Length of basitarsus : length of inner hind tibial spur: $5: 3$. Subapical tooth of claw shorter than apical (Fig. 12). Serrulae 5-7 with 5 larger teeth (Fig. 1). Length: $12.5 \mathrm{~mm}$, lenght of fore wing: $12.0 \mathrm{~mm}$.

The new species is similar to Tenthredo (Tenthredella) pulchra Jakovlev, 1891. Tenthredo pulchra has abdominal sternites black and red. Clypeus, mandibles and labrum are black (clypeus sometimes with 2 white spots). Mesoscutellum densely granulated and absolutely matt. Legs without red. Head behind the eyes is contracted. Stigma and costa are black. The new species has all abdominal sternites, clypeus, mandibles and labrum white. Mesoscutellum is shiny that is in very strong contrast with the densely punctured matt mesonotum. Legs extensively red. Head behind eyes is clearly dilated. Stigma and costa are reddish brown. The specific name refers to the type locality.

\subsection{Tenthredo (Tenthredella) sinosimplex spec. nov.}

(Fig. 4, 13,19)

Material.- Holotype, female (KIZ): "China, Gansu Province, Xiahe (= Labrang) env., $35^{\circ} 11.3^{\prime} \mathrm{N}, 102^{\circ} 30.6^{\prime} \mathrm{E}$, 3043 m (GPS), 19-22. vi. 2005, J. Hájek, D. Král and J. Rúzitschka leg. ". Paratypes: 2 females, topotypic, (HNHM) and (SNM).

Female (Fig. 19). Head black. Supraclypeal area, genae, narrow inner orbits in total length, narrow outer orbits up to half height of eye white. Clypeus white with narrow black basal margin and with 2 small black spots. Labrum white with black basal margin. Mandlible white with brown apex. Antenna black, dorso-apical spot on segment 4 white, segments 5-7 dorsally white. Thorax black, hind narrow pronotal margin and narrow basal margin of tegula white. Legs dominantly black, dirty white: coxae (hind coxae with narrow longitudinal black line), all trochanters, ventral sides of all femora and tibiae. Wings hyaline, costa, subcosta, stigma and other veins brownish black. Abdominal tergites 3-5 and lateral sides of tegite 2 red, other tergites black, 8th and 9th tergites each with 2 whitish brown spots. Abdominal sternites pale brownish red. Ovipositor reddish brown with black apical and ventral margin. Head very densely, moderately deeply and uniformly punctured all over, moderately shiny. Mesonotum matt, densely granulated and scattered with sporadic larger punctures. Mesoscutellum and mesoscutellar appendage with longitudinal keel, densely, uniformly punctured with moderately deep, small punctures, hardly shiny. Metascutellum with moderately deep, pin-bit like punctures, moderately shiny. Mesopleuron hardly shiny, very densely covered with deep and also moderately deep and moderately large punctures. Abdominal tergites from second tergite with fine microstriation, shiny. Propodeum with fine, undefined surface sculpture, shiny. Ratio of antennal segments: $11: 10: 29: 18: 19: 14$ : 12 : $11: 11$. OOL : POL : OCL: $3: 1: 2$. Antenna about as long as head and thorax combined excluding propodeum and metanotum. Length and width of postrocellar area: $13: 22$. Head contracted behind eyes with hardly visible occipital carina. Postocellar furrows slightly divergent, deep and reaching hind margin of head. Supraantennal tubercles small, confluent with frontal area. Clypeus long, anterior margin wide and shallow about $0.25 \mathrm{x}$ as deep as clypeal median length. Gena about $2 \mathrm{x}$ as long as diameter of front ocellus. Mesoscutellum and mesopleuron flat witout thorn. Head and thorax covered with short, sparse and whitish pubescence about half as long as diameter of front ocellus. Length of ovipositor : length of hind tibia: 38 : 47. Subapical tooth of claw shorter than apical (Fig. 13). Serrulae 5-7 with 15-16 minute teeth (Fig. 4). Length: $9.0 \mathrm{~mm}$, length of fore wing: $9.0 \mathrm{~mm}$.

Paratypes: like holotype but 5th antennal segment may entirely or dominantly black. Length: $9.8-10.0 \mathrm{~mm}$. Length of fore wing: $10.0 \mathrm{~mm}$.

The new species is similar to the Palaearctic Tenthredo simplex Dalla Torre, 1882. The mesonotum of Tenthredo simplex is subshiny, finely and densely granulated without larger punctures. Tergite 3-6 and sternite 3 and dominantly the 4th are red. Other parts of abdomen are black. Clypeus and labrum are entirely white without any black spots or margin. Head is shiny only superficially granulated. Pronotum without white margin. All tarsi and tibiae are entirely red. The new species has mesonotum matt, densely granulated and scattered with sporadic, larger punctures. Abdominal tergites 3-5 and lateral sides of tegite 2 are red, other tergites are black. Eigth and 9th tergites with 2-2 whitish brown spots. Abdominal sternites are pale brownish red. Ovipositor is reddish brown with black apical and ventral margin. Clypeus white with narrow black basal margin and 2 small black spots. Labrum white with black basal 
margin. Head is very densely, moderately deeply and uniformly punctured all over, moderately shiny. Pronotum with white hind margin. Femora are ventrally red and dorsally black. Tenthredo simplex Dalla Torre earlier was considered to be a colour variation of Tenthredo balteata Klug, 1817. Tenthredo balteata Klug well agrees with Tenthredo simplex Dalla Torre in the densely granulated mesonotum without having larger punctures but the red colour is missing from the entirely black abdomen. The specific name refers to the distribution: sino means Chinese and its similarity to Tenthredo simplex.

\subsection{Tenthredo (Tenthredella) rolleri spec. nov. (Fig. 5,}

$6,15,20)$

Material.- Holotype, male (KIZ): "China, Qinghai Province, Gangca Dasi (=Iamasery) 3505-3840 m., 37 32.4' -33.0' N, $100^{\circ} 05.3^{\prime} 06.0^{\prime} \mathrm{E}$ (GPS), 11-12. vii. 2005, J. Hájek, D. Král and J. Rúzitschka leg. ”. Paratypes: male (SNMB), 2 females (SNMB, HNHM), topotypic.

Male (Fig. 20). Body light green with black pattern. Black: wide postoccipital, frontal and supraantennal furrows, entire clypeus, labrum (only mandible green), scape, pedicel, dorsal side of flagellar segments of antenna, all mesonotal furrows, lateral sunken sides of lateral mesonotal lobes, dorsal longitudinal strips on all coxae, femora, tibiae and also on middle and hind tarsi, narrow sutures of pro-, meso- and metapleuron, postnotum (except green cenchri, mesoscutellar appendage and metascutellum), basal strip on first abdominal tergite (triangularly widening in middle), large subtriangular median spot on tergite 2 and basal strip on tergite 3 (also widened in middle). Wings hyline, venation black, stigma, apical third of costa green. Clypeus widely, roundley and shallowly emarginated and about $0.25 \mathrm{x}$ as deep as clypeal median length. Ratio of antennal segments: $10: 10: 24: 22: 19: 15: 13: 11: 9$. OOL : POL : OCL: $13: 4: 10$. Width and length of postocellar area: $2: 1$. Gena about as long as diameter of front ocellus. Head moderately shiny, moderately deeply and densely punctured with small or middle sized punctures. Head behind eyes clearly contracted with sharp hind carina. Supraantennal tubercle well separated from frontal area. Length and height of supraantennal tubercle: 11: 5. Mesoscutellum and mesopleuron flat. Mesosternum without thorn. Mesonotum and mesoscutellum moderately shiny with dense, fine and moderately deep punctures. Mesoscutellar appendage hardly shiny, smooth with few small punctures on hind margin. Metascutellum with few, sporadic moderately large and moderately deep punctures, moderately shiny. Mesopleuron moderately shiny with fine, shallow and moderately dense punctures. First abdominal tergite with fine microstriation, moderately shiny. Other tergites with moderately deep moderately large and also with few, sporadic deep and large punctures, moderately shiny. Head and thorax covered with greyish, moderately dense pubescence. Pubescence about $2 / 3 x$ as long as diameter of front ocellus. Hind tibial spurs short, length of inner hind tibial spur : length of basitarsus: $12: 35$. Claws bifid, subapical tooth of claw as long and as wide as apical tooth or even slightly shorter (Fig. 15). Subgenital plate short and widely rounded without apical incision. Penis valve in Fig. 6. Length: $8.6 \mathrm{~mm}$. (Male paratype: $7.2 \mathrm{~mm})$.

Females: similar to males, but: abdominal tergites with continuous black dorsal band, sawsheath, clypeus, labrum, ventral part of scape and ventroapical part of pedicel, entire costa, apical third of subcosta green. Subapical tooth of claw little shorter than apical. Length of ovipositor: length of hind tibia: $27: 40$. Serrulae 5-7 with 4 larger irregular teeth (Fig. 5). Antennal joints 3: 4 as $24: 17$. Body length: $8.9-9.5 \mathrm{~mm}$.

The new species runs to Tenthredo nigromaculata Smith, 1878 in Malaise's key (Malaise, 1945). The differences are: the new species, in opposite of $T$. nigromaculata Smith, has no large black frontal spot, only the sutures of the frontal area are black, mesopleuron of the new species without dorso-ventral black strip, abdominal tergites without semicircular basal spots but with continuous black band in females, finally, the new species has absolutely flat mesoscutellum definitely not roundly elevated as in $T$. nigromaculata Smith.

It's closest relative is Tenthredo flatopectalina Wei, 2002 (Wei \& Nie, 2002). Only the penis valve differs the 2 species. T. flatopectalina has strongly sclerotised and pigmented penis valve with distinctly rounded dorsal margin. The penis valve of the new species weekly sclerotised, mostly hyaline with straight hind margin (comparing Fig. 6,9). Furthermore, T. flatopectalina Wei is larger, $12 \mathrm{~mm}$. The new species is dedicated to Dr. Ladislav Roller, Slovak Symphyta specialist. Tenthredo pseudograhami Wei, 2002 is also related to the new species. The penis valve of the 2 species is completely different (compare Fig. 6,8): the apical projection placed in the middle, the body is sclerotised, dark in $\mathrm{T}$. pseudograhami Wei but the projection is placed laterally and the body of the penis valve is hyaline in the new 
species. Larger, 11-12 mm. The serrulae of $\mathrm{T}$, pseudograhami with high number, 12-13 small teeth but only 4-5 larger, irregular shaped teeth are placed on the serrulae of the new species (compare Fig. 5 and Fig. 5 in Wei \& Nie, 2002).

\subsection{Tenthredo (Tenthredella) qinghaiensis spec. nov.}

(Fig. 3,14)

Material.- Holotype, female (KIZ): "China, Qinghai Province, Gangca Dasi (=Iamasery) 3505-3840 m., $37^{\circ} 32.4^{\prime}-33.0^{\prime} \mathrm{N}, 100^{\circ} 05.3^{\prime} 06.0^{\prime} \mathrm{E}$ (GPS), 11-12. vii. 2005, J. Hájek, D. Král and J. Rúzitschka leg. ”.

Female. Head black. Clypeus, labrum, basal 2/3 of mandible and palpi white. Apex of mandible brown to black. Antenna black. Thorax black, hind margin of pronotum and tegula white. Cenchri grayish. All coxae, trochanters, femora and hind tarsus black, fore and middle tarsi white below black above, fore tibia white with dorsal black line, middle tibia white with dorsal black line on apical third, hind tibia white with black apical third and narrow basal ring. Abdomen including ovipositor black, last abdominal tergite white, abdominal segments 3-5 red. Wings slightly infuscate, subhyaline, costa, subcosta, stigma and other veins dark brown. Head including frontal area, vertex, inner orbits and temples roughly, deeply and densely punctured, hardly shiny. Mesonotum matt, very finely granulated. V-shaped lateral margin of anterior mesonotal lobes with dense, moderately deep punctures, weekly shiny. Mesoscutellum and mesoscutellar appendage densely, roughly punctured with moderately deep and moderately large punctures, weekly shiny. Metascutellum finely and horizontally wrinkled with moderately dense small punctures, weekly shiny. Upper third of mesopleuron roughly and densely punctured with large, deep and moderately large and moderately deep punctures (combined), weekly shiny. Lower $2 / 3$ of mesopleuron very finely and densely granulated, matt. First abdominal tergite (propodeum) shiny with fine granulation, other tergites shiny with fine microstriation. Antenna shorter than head and thorax combined, ratio of antennal segments: $11: 7: 22: 14: 14: 12: 10: 10: 9$. OOL : POL : OCL: $17: 5: 9$. Width and length of postocellar area: $17: 9$. Head with distinct hind carina. Clypeus widely and slightly emarginated to a depth about $0.25 \mathrm{x}$ clypeal median length. Supraantenal tubercles small, confluent with frontal area. Gena half as wide as diameter of front ocellus. Head subparalell behind eyes and contracted at temples. Mesoscutellum hardly raised, nearly flat. Mesopleuron flat, mesosternum without thorn.
Head and thorax covered with short, sparse, white pubescence. Length of ovipositor : length of hind tibia: 53 : 85. Serrulae 5-7 with 10-13 minute teeth (Fig. 3). Subapical tooth of claw shorter than apical (Fig. 14). Length: $9.5 \mathrm{~mm}$.

The new species is similar to Tenthredo (Tenthredella) pulchra Jakovlev, 1891. Tenthredo pulchra has tegula, hind tibia, tarsi, costa, clypeus and labrum black although sometimes clypeus is coloured with 2 pale white spots. Larger, 11-12 $\mathrm{mm}$ species. The new species has tegula, clypeus and labrum white. Fore and middle tarsi are also white but dorsally black coloured. Costa is yellow. Smaller species, $9.5 \mathrm{~mm}$ long. The specific name refers to the type locality.

\subsection{Tenthredo (Tenthredella) yunningsiensis spec. nov.}

(Fig. 7, 16, 21)

Material.- Holotype, male (KIZ): "China, Qinghai Province, Yunning Si (Iamasery) $2890 \mathrm{~m} ., 36^{\circ} 45.6^{\prime} \mathrm{N}$, $102^{\circ} 10.6^{\prime}$ E (GPS), 01-02. vii. 2005, J. Hájek, D. Král and J. Rúzitschka leg." .

Male (Fig. 21). Head black above. Narrow complete inner orbit, narrow outer orbit up to half of eye and face below antenna white. Head behind outer orbits, clypeus, labrum, mandibles, palpi light brown. Scape and pedicel black. Flagellar segments of antenna black above and white below. Thorax black above except white pronotal margin and tegula. Lateral and ventral parts of thorax ligth brown except dorso-ventral black line on mesopleuron. Legs ligth brown, coxae, trochanters, femora, fore and middle tibiae, fore and middle tarsi all with black longitudinal line. Abdomen ligth reddish brown. Propodeum, large reverse subtriangular spot on tergite 2, apical half of tergite 7, tergites 8 and 9 entirely black. Abdominal sternites without black spot. Wings hyaline. Subcosta and venation dark brown. Head very densely and uniformly punctured with moderately deep and moderately large punctures, moderately shiny. Mesonotum and mesoscutellar appendage very densely and uniformly punctured with small and moderately deep punctures, nearly granulated moderately shiny. Metascutellum shiny with minute and deep sporadic punctures. Mesopleuron shiny, with shallow, dense punctures. Costa and stigma ligth brownish yellow. Ratio of antennal segments: $9: 7: 21: 19: 14: 10: 10: 9: 9$. Antenna about as long as head and thorax combined (excluding propodeum). OOL : POL : OCL: $12: 5: 7$. Head strongly contracted behind eyes with distinct hind carina. Supraantennal tubercles confluent with frontal area. Clypeus roundly emarginated. Basal width of 
clypeus: distance between eyes at level of antennal sockets: 23 : 28 . Clypeal emargination about $0.4 \mathrm{x}$ as deep as clypeal median length. Gena about half as wide as diameter of front ocellus. Mesoscutellum and mesopleuron flat. Mesosternum without thorn. Head and thorax covered with sparse, short, white pubescence. Subapical tooth of claw nearly as long as apical (Fig. 16). Penis valve in Fig. 7. Length: 7.6mm.

The new species runs to Tenthredo nigrobasalis Malaise, 1945 in Malaise's key (Malaise, 1945). T. nigrobasalis is larger, $10-11 \mathrm{~mm}$. It has 2-3 basal tergites with white sides that is missing in the new species. Hind tibia and tarsus black in T. nigrobasalis but red in the new species. Mesopleuron strongly punctured in $T$. nigrobasalis but shallowly, finely and densely punctured in the new species. In genitalia, the new species somehow resembles to Tenthredo reversimaculeta Wei, 2002 (Wei \& Zhong, 2002) (compare Fig. 7,10). T. reversimaculeta has mesoscutellum, triangular spots on tergites, trochanters and hind tibia white. These parts are black or reddish coloured in the new species. $T$. reversimaculeta is larger, $12-14 \mathrm{~mm}$. The specific name refers to the locus typicus (type locality).
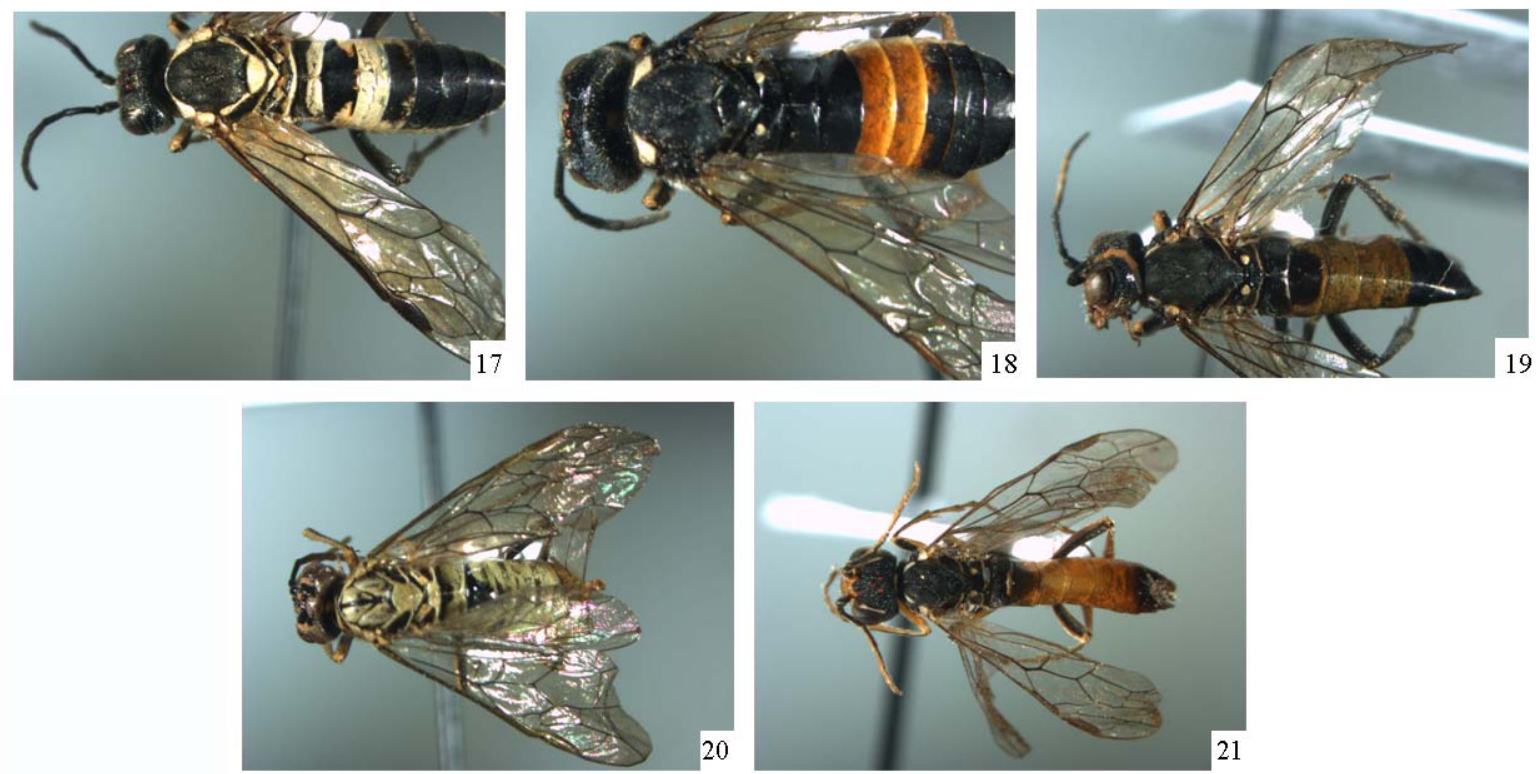

Figs. 17-21: Four holotypes and one paratype of Tenthredo genus

17: $T$ sinotemula sp. nov. (holotype) (photo: Roller); 18: T. labrangensis sp. nov. (holotype) (photo: Roller); 19: T. sinosimplex sp. nov. (holotype) (photo: Roller); 20: T. rolleri sp. nov. (paratype) (photo: Roller); 21: T. yunningsiensis sp. nov. (holotype) (photo: Roller).

\section{Conclusion}

In this early period of the research, we can not draw many conclusions since further, intensive faunistic research is necessary to learn the zoogeographical distribution of the species. From the faunistic list, it seems to be clear, the sawfly fauna conisists Holarctic [Pachynematus (Pachynematus) vagus (Fabricius, 1781)], Oriental (Athalia antennata Cameron, 1902; Siobla atra Malaise, 1945; Tenthredo rufoviridis Malaise, 1945 and Tenthredo (Tenthredella) pulchra Jakovlev, 1891) and also East-Palaearctic elements (Athalia rosae ssp. ruficornis Jakovlev, 1888; Tenthredo (Temuledo) brachycera (Mocsáry, 1808) and Tenthredo trunca Konow, 1908). The ratio of the potential endemic elements is also high (see the described new species and Taxoblenus rufipes Wei and Nie, 1999).
Corrections to the previous papers (Haris \& Roller, 2007; Haris, 2007): 1) Haris \& Roller, 2007: On page 169, change "Taxoblenus longispinosus Wei and Nie, 1999"to “Taxoblenus longicornis Wei and Nie, 1999”; 2) Haris, 2007: On page 156, change "Monophadnus funebris Konow, 1898 Lectotype: 1 female (RMNH)" to "Monophadnus funebris Konow, 1898 Lectotype: 1 female (DEI)".

Acknowledgements: I express my grateful thanks to Dr. Ladislav Roller for transferring the sawfly material. Many thanks for reviewing and correcting of the manuscript to Dr WEI Mei-cai (Central South Forestry University, Changsha, China) and also to Dr David R. Smith (National Museum of Natural History, Washington, U.S.A.) for his corrections. Finally, grateful 
thanks to Dr. NIE Long for his efforts in correcting and

\section{References:}

Haris A, Roller L. 1998. Three new Tenthredo species from Yunan (Hymenoptera: Tenthredinidae) [J]. Folia Entomologica Hungarica, 59: 135-140.

Haris A, Roller L. 1999a. Two new sawflies from Yunan (Hymenoptera: Tenthredinidae) [J]. Acta Zoologica Academiae Scientiarum Hungariae, 45 (3): 217-219.

Haris A, Roller L. 1999b. Four new sawfly species from Yunnan (Hymenoptera: Tenthredinidae) [J]. Folia Entomologica Hungarica Supplement, 60: 231-237.

Haris A. 2007. Sawflies (Hymenoptera: Symphyta: Tenthredinidae) from Indonesia, Malaysia and Vietnam [J]. Zoologische Mededelingen, 80(8): 149-159.

Haris A, Roller L. 2007. Sawflies from Gansu Province, China (Hymenoptera: Tenthredinidae) [J]. Natura Somogyiensis, 10: 165-172.

Huang N, Wei M. 2007. A new species of Taxonus Hartig (Hymenoptera: Tenthredinidae) from China [J]. Entomotaxonomia Yangling and Shaanxi, 29 (3): 227-230.

Malaise R. 1945. Tenthredinoidea of South-Eastern Asia with a general zoogeographical review [J]. Opuscula Entomologica, 4: 1-278. editing my paper.
Nie H, Wei M. 2002. Six new species and subspecies of the genus Tenthredo L. (Hymenoptera: Tenthredinidae) from Henan Province [A]. In: Shen X, Zhao Y. Insects of the Mountains Taihang and Tongbai Regions in the Fauna and Taxonomy of Insects in Henan [C]. China Agricultural Science and Technology Press, 5: 138-147.

Wei M, Nie H. 2002. Five new species of the genus Tenthredo L. (Hymenoptera: Tenthredinidae) from Henan Province [A]. In: Shen X, Zhao Y. Insects of the Mountains Taihang and Tongbai Regions in the Fauna and Taxonomy of Insects in Henan [C]. China Agricultural Science and Technology Press, 5: 154-162.

Wei M, ZhongY. 2002. Nine new species of Tenthredo from Henan Province (Hymenoptera: Tenthredinidae) [A]. In: Shen X, Zhao Y. Insects of the Mountains Taihang and Tongbai Regions in the Fauna and Taxonomy of Insects in Henan [C]. China Agricultural Science and Technology Press, 5: 242-252.

Zhelochovtsev AN. 1988. Pereponchatokrylye [A]. In: Medvedev GC. Opredelitel Nasekomych Evropejskij Tscasti SSSR [C]. Nauka, Leningrad, 3(6): 234.

\section{Appendix I Sawflies (Tenthredinidae) from Gansu and Qinghai Provinces}

Athalia antennata Cameron, 1902: 2 males, Gansu Province, Lazikou valley, 2150 m, 34 09.9-10.1' N, 103 48.2-51.9' E, 28. vi. 2005.

Athalia rosae ssp. ruficornis Jakovlev, 1888: 1 female, Gansu Province, Sangke env., 35 06.7' N, $102^{\circ} 25.1^{\prime}$ E, $3057 \mathrm{~m}, 21$. vi. 2005

Taxoblenus rufipes Wei and Nie, 1999: 1 female, Gansu Province, Xiahe (= Labrang) env., 35¹1.3'N, 102 30.6'E, 3043 m (GPS), 19-22. vi. 2005

Siobla atra Malaise, 1945: 1 female, Gansu Province, Lazikou valley, $2150 \mathrm{~m}, 34^{\circ} 08.8^{\prime} \mathrm{N}, 103^{\circ} 54.5^{\prime} \mathrm{E}, 27$. vi. 2005.

Tenthredo (Temuledo) brachycera (Mocsáry, 1808): 1 female, Qinghai Province, Hunagyhong env., Taer Si (Iamasery, Kumbum), 2665-2780m, 36 $28.8-29.5^{\prime} \mathrm{N}, 101^{\circ} 34.0-34.1^{\prime} \mathrm{E}, 17$. vii. 2005.

Tenthredo (Tenthredella) pulchra Jakovlev, 1891: 2 females, Gansu Province, Mts., 2000-3000m, 19-28. vi. 2005, 2 females, Qinghai Province, Yunning Si (Iamasery) 2890m., 36 $45.6^{\prime} \mathrm{N}, 102^{\circ} 10.6^{\prime} \mathrm{E}, 01-02$. vii. 2005.

Tenthredo rufoviridis Malaise, 1945: 1 female, Gansu Province, Dagcanglhamo (Langmusi) env. 34 04.6-05.1' N, 102 ${ }^{\circ} 37.7-38.1^{\prime} \mathrm{E}, 3464-3644 \mathrm{~m}$, 25. vi. 2005.

Tenthredo trunca Konow, 1908: 1 female, Gansu Province, Lazikou valley, 2150 m, 34 09.9-10.1' N, 103 48.2-51.9' E, 28. vi. 2005.

Pachynematus (Pachynematus) vagus (Fabricius, 1781):1 female, Gansu Province, Xiahe (= Labrang) env., 35²11.3'N, 102 30.6'E, 3043 m, 19-22. vi. 2005. 